\title{
NIRS: Forage analysis and livestock feeding
}

\author{
D.C. CORSON, G.C. WAGHORN, M.J. ULYATT and J. LEE \\ AgResearch Grasslands, Private Bag 11008, Palmerston North
}

\section{Abstract}

This paper describes analysis by near infrared reflectance spectroscopy (NIRS) and demonstrates the capacity of this technology to provide rapid, low cost and accurate estimates of feed composition. The need for an extensive database against which the instruments is calibrated and the importance of good wet chemistry backup to NIRS are emphasised, together with some of the diverse uses for NIRS in research and agriculture. Examples are given of contrasting analyses for quality of maize silage and pastures. NIRS prediction of pasture, silage and supplement composition can be used in conjunction with a ration balancing model developed for the New Zealand dairy industry, allowing farmers to formulate diets able to meet desired levels of production.

Keywords: dairy, feed quality, forage analysis, NIRS, nutrition

\section{Introduction}

High levels of animal performance and health are dependent on high quality nutrition and management. Nutrition is often limiting the productivity of ruminants selected for high genetic merit (Ulyatt \& Waghorn 1993), whether it be expressed as milk production, multiple births, growth rate or disease resistance. Livestock farmers are aware of the importance of forage quality, but until recently it was not easy to obtain quantitative information at an affordable price. NIRS analysis has addressed the issue of cost, insofar as the technique can provide reliable estimates of feed composition at about one fifth of the cost of conventional chemical analyses to determine the amount of structural fibre, soluble carbohydrate, crude protein, lipid and ash. NIRS can also predict the digestibility and metabolisable energy (ME) value of a feed (Ulyatt et al. 1995). NIRS analysis is increasingly used to balance rations for dairy cattle in New Zealand and elsewhere, and this has prompted a refinement of feed budgeting models to include feed quality as well as quantity, and make models more amenable for farmers and consultants to optimise livestock feeding using their own personal computer.

This paper summarises the diversity of uses of NIRS in feed production with a focus on its value for pastoral agriculture. Examples include screening new plant selections for improved nutritive value, providing information on silages and crops for either ration balancing or for determining an economic value and selling price. The basis of the NIRS technique will be explained, especially the need for a calibration database using New Zealand feeds, which is therefore appropriate for predicting the composition of New Zealand forages. Examples of NIRS outputs will be given to indicate contrasting nutritive value of apparently similar crops, together with a brief resume of the feedTECH rationbalancing model used to interpret these analytical data.

\section{feedTECH}

Data presented here are derived from the feedTECH system based at AgResearch in Palmerston North. This system comprises an NIRS in association with a chemical laboratory (International accreditation NZ) and a computer driven ration balancing programme which has been developed to aid in the interpretation of NIRS data. The model has been built at AgResearch and is based on estimates of nutrient requirements for lactating cows from Australia (Robards \& Radcliffe 1990; Hume et al. 1986), the United Kingdom (ARC 1980; AFRC 1993) and the USA (NRC 1989). Principal components used in feed budgeting are protein, energy and, to a lesser extent, the mineral requirements of lactating cattle. The model has been validated with data from the Dairying Research Corporation and Massey University, and beta-tested by experienced consultants. It is due to be released in August 1999.

The model has been developed for the dairy industry because good nutritional data can be readily obtained, dairy farmers receive routine advice from the Livestock Improvement Corporation and because dairy farming is amenable to feed supplementation (Clark et al. 1997).

\section{NIRS analysis}

NIRS analyses requires a sample $(0.5-1.0 \mathrm{~g})$ which is exposed to an electro-magnetic scan over a spectral wavelength range of 1100 to $2500 \mathrm{~nm}$ (near infrared). Energy in this spectral range is directed on to the sample and reflected energy $(R)$ is measured by the instrument. The diffuse reflection carries information which 
identifies chemical bonds within the sample, such as $\mathrm{CH},-\mathrm{OH},-\mathrm{NH}$ and $-\mathrm{SH}$. The reflected energy is stored as the reciprocal logarithm $(\log 1 / \mathrm{R})$ and the spectra (Figure 1) are transformed to provide information about the chemical composition of the sample (Baker \& Barnes 1990; Shenk \& Westerhaus 1993). Absorption bands due to water $(1450 \mathrm{~nm})$ and protein functional groups (2100 to $2200 \mathrm{~nm}$ ) are identified on Figure 1.

The absorbance associated with chemical bonds in the forage sample form the bases of all organic material and enable identification of sugars, structural fibres, proteins, lipids and some of their component fractions. Identification requires the NIRS instrument to be calibrated by relating the spectra to chemical analyses by wet chemistry, or in vivo data (e.g., digestibility, or metabolisable energy (ME) values). The NIRS technique for analysis is absolutely dependent on good quality reference laboratory or animal data.

The two main benefits of NIRS analysis are speed and cost. For example, conventional analysis of feed composition (fibre, nitrogen, sugars, lipid and ash) will take about 16 hours, with each of the five assays run concurrently, where as this can be completed in 2-3 minutes by NIRS on suitably prepared samples. Forages can be analysed fresh, dried, or dried and ground, but each preparation will yield a different spectrum (Ulyatt et al. 1995) so the type of preparation should be defined before calibration of the instrument database. Liquid samples, such as milk, can be scanned for compositional analyses providing that appropriate spectral and chemical analytical data have already been entered in to the database. Some examples of diverse uses of NIRS in agriculture are given in Table 1.

\section{Calibration of the NIRS database}

The accuracy of NIRS estimation of feed composition is dependent upon the data used to calibrate the instrument. Best predictions are obtained when separate data sets are used for each forage type. For example the feedTECH NIRS is calibrated against five feed types: pasture, pasture silage, brassica, corn silage and grain. Over 200 samples each of pasture, pasture silage and maize silage have been analysed by wet chemistry and their spectra scanned into the NIRS, as well as 100 samples of high energy grain-based supplements and 80 samples of brassica (kale, rape, chow mollier, turnips, swedes). Wet chemistry was used to determine sample composition in terms of dry matter, organic matter, ash, crude protein, lipid, soluble sugars, starch, neutral detergent fibre (NDF), acid detergent fibre (ADF) and mineral element content. Additional analyses were undertaken with silages, to include $\mathrm{pH}$, lactic and volatile fatty acids and ammonia concentrations. Wet chemistry
Figure 1 Typical NIRS pasture spectrum showing the relationship between absorbance and increasing wavelength.

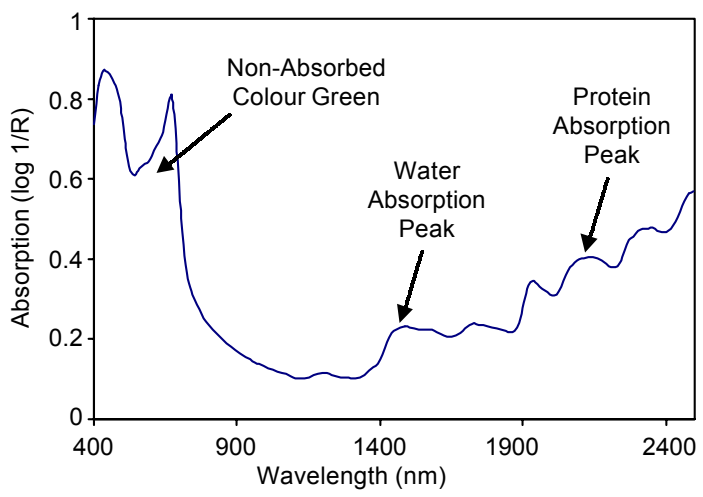

Table 1 Some uses of NIRS analyses in agricultural and food industries. Sourced from the Commonwealth Agricultural Bureau database.

Quality assessment of grains, tomatoes, peas, potatoes, sugar etc.

Fatty acid composition of sunflower oil.

Amino and fatty acid composition of soybean seed.

Analysis of butter for fat, moisture and salt.

Analysis of curds during cheese making.

Estimating lignin content of forest products.

Screening foods for mould contamination.

Determining the nutritive value of forages for ruminants.

Identifying plants having desirable traits for selection.

Analysis of faeces to estimate dietary composition.

Prediction of botanical composition of grass/legume samples.

Digestible amino acid content of feeds for poultry.

Mastitis diagnosis in cow milk.

Measuring yield and fibre diameter in wool.

Differentiating between goose and porcine products.

Measuring brain oxygenation in calves.

analyses were entered into the NIRS database to derive a relationship with the absorbance spectra.

The calibration is based on principal component analysis using a first derivative modified partial least squares mathematical interpretation (Shenk \& Westerhaus 1991). Examples of calibration curves (Figure 2) indicate the range within each sample type which have been entered into the spectral database, and show that the goodness of fit differs for forage types and individual analyses (Table 2). Differences between forage types in predictions $\left(\mathrm{R}^{2}\right)$ of constituents are due to a variety of factors. These include the range of values within a forage type and interference due to other constituents. For example the presence of volatile fatty acids will influence the dry matter determination because of losses during drying, and this affects estimates of composition. Examples of the predictive capability of NIRS given in Table 2 and Figure 2 show a close relationship between 
Figure 2 Relationships between predicted NIRS and laboratory values for pasture and maize silage crude protein (CP) and NDF (neutral detergent fibre) concentrations. Points represent individual analyses used in the calibration. $\mathrm{R}^{2}$ (goodness of fit) are given in Table 2.
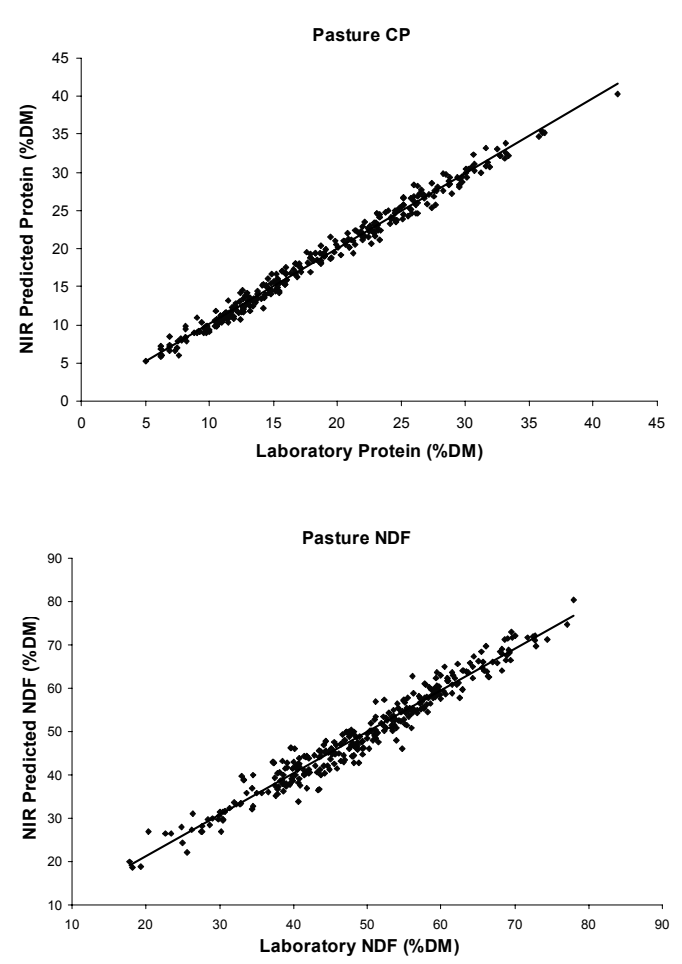

NIRS prediction and wet chemistry analyses in some, but not all instances. The high $\mathrm{R}^{2}$ values for NDF in pasture and in maize silage indicate excellent predictive capability compared to some other constituents. In general the $\mathrm{R}^{2}$ is increased as more information is added to the database. In 1995, the feedTECH NIRS $\mathrm{R}^{2}$ for soluble sugars was 0.55 (Ulyatt et al. 1995) and this has risen to $0.87-0.88$ (Table 2), but the prediction is also affected by the type of constituent and the range in actual values. For example, the low $\mathrm{R}^{2}$ for $\mathrm{pH}$ in maize silage $(0.38$, Table 2$)$ is not due to a high error, but to a small range in sample values (3.6-4.2). The error relative (defined standard error/sample mean $\times 100$ ) is only $3 \%$ in this case (NIRSystem 1995), well within the defined margin of error $( \pm 5 \%)$ considered acceptable. Any samples falling outside the margin of error, defined as outliers, are subjected to chemical analyses.

Whilst most predictions are based on a direct correlation between the spectra and the chemical constituent, some predictions are more generalised. For example dietary cation/anion difference (DCAD) represents a balance of dietary anions and cations (Wilson 1996), and this prediction is dominated by the
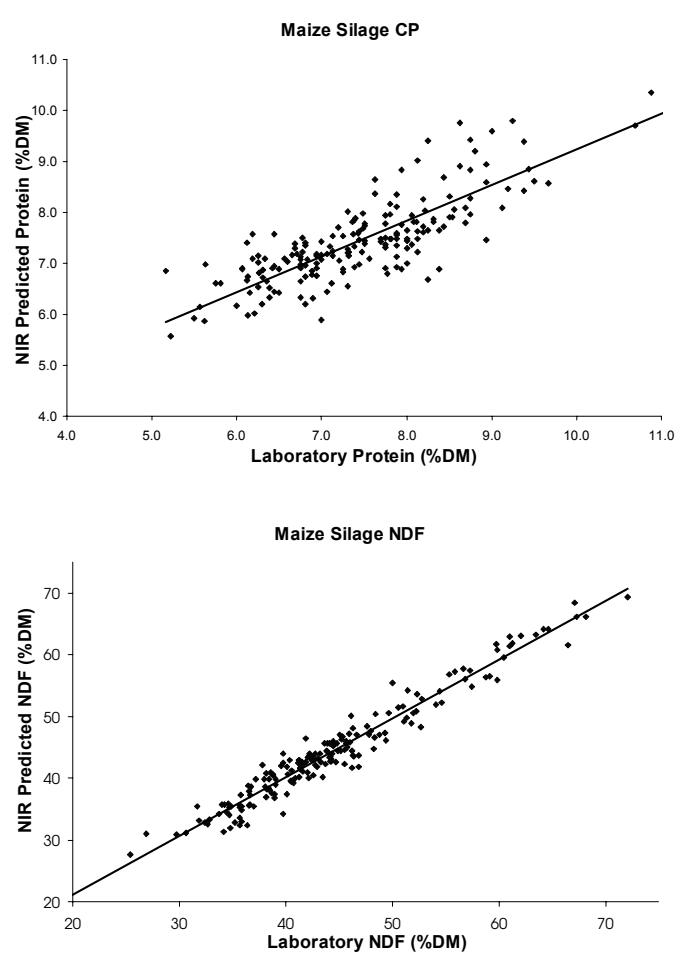

Table 2 Chemical composition of pasture and maize silage samples determined by laboratory analysis with NIRS cross validation error (SECV) and correlation statistics $\left(R^{2}\right)$. All values are\% of dry matter, except $\mathrm{pH}$ and $\mathrm{DCAD}$ (milli equivalents/kg DM).

\begin{tabular}{lccccc}
\hline & $\begin{array}{c}\text { No. of } \\
\text { samples }\end{array}$ & Mean & Range & $\mathrm{R}^{2}$ & SECV $^{1}$ \\
\hline Pasture & & & & & \\
$\quad$ Crude protein & 339 & 18.5 & $5.0-36.2$ & 0.99 & 0.95 \\
NDF & 360 & 49.4 & $17.8-78.0$ & 0.95 & 2.79 \\
Soluble sugars & 358 & 8.5 & $1.0-25.0$ & 0.87 & 1.38 \\
OMD & 31 & 72.3 & $55.0-85.0$ & 0.90 & 3.37 \\
DCAD & 87 & 449 & $200-800$ & 0.90 & 57.58 \\
Maize silage & & & & & \\
Crude protein & 182 & 7.5 & $4.4-13.1$ & 0.67 & 0.61 \\
NDF & 185 & 44.3 & $18.7-72.1$ & 0.95 & 2.10 \\
Soluble sugars & 191 & 35.0 & $1.2-61.7$ & 0.88 & 4.79 \\
Lactic acid & 77 & 3.8 & $0-10.7$ & 0.82 & 0.85 \\
pH & 69 & 3.8 & $3.6-4.2$ & 0.38 & 0.08 \\
\hline
\end{tabular}

${ }^{1}$ SECV $=$ Standard error of cross validation

influence of potassium. When potassium concentration increased, DCAD increased and vice versa. The correlation $\left(\mathrm{R}^{2}\right)$ between potassium concentration and 
DCAD was 0.78 . Other examples include ME or organic matter digestibility (OMD), neither of which are directly measurable components of a forage. The bases for these predictions differ for feed types. With pasture, the NIRS database has included about 35 feeds for which in vivo digestibility were known, and samples of the feed were available for scanning. These samples were from published information based on animal trials carried out at AgResearch, the Dairying Research Corporation and Massey University, and the spectra from the feeds enabled prediction of OMD. The ME was derived directly from predicted OMD. The ME for pasture supplements (e.g., pasture silage) was calculated on the basis of an in vitro cellulase digestibility assay (Dowman \& Collins 1982; Roughan \& Hollan 1977) which had been calibrated against in vivo standards. The ME for maize silage was calculated from NIRS predicted ADF concentrations (NIRSystem 1995).

\section{Feed analysis and interpretation of data}

The first requirement for determining dietary composition is to obtain a representative sample of either material eaten or on offer. Pasture samples are best plucked to a level grazed by livestock from several sites within the area to be evaluated, but silages must be sampled from within a well-managed silage facility, not from the exposed face. A well-managed stack will have a small exposed face, so animals are not fed silage that has deteriorated through prolonged exposure to the weather. The samples should be sealed in a courier bag, chilled in a refrigerator and shipped to the NIRS technician for drying at $60^{\circ} \mathrm{C}$ (to minimise alterations in chemical composition), followed by grinding and scanning. The spectral information will be compared with the database for the appropriate feed type and a predicted composition reported (e.g., Table 3). Any prediction outside the defined margin of error is deemed an outlier and will be submitted for chemical analysis. Outliers can arise because of a different feed type (e.g., containing a high concentration of condensed tannins) or because the sample composition has a composition different from normal material upon which the database was developed. After thorough quality control tests have been completed on outlier samples, results may be added to the database thus strengthening the ability of the technique to predict more accurately the composition of similar samples in future.

The composition of feed-stuffs is described by 8 12 variables which provide information about feed quality. This information can be used in several ways. The chemical analyses provided by feedTECH is mailed to clients together with an explanatory sheet defining the range of values normally encountered for each
Table 3 Contrasting analyses of maize silage and pasture samples submitted to feedTECH for NIRS analyses.

\begin{tabular}{|c|c|c|c|c|}
\hline \multirow[b]{2}{*}{ Component } & \multicolumn{2}{|c|}{---- Maize silage ---- } & \multicolumn{2}{|c|}{-------- Pasture -------- } \\
\hline & Sample 1 & Sample 2 & Sample 1 & Sample 2 \\
\hline Dry matter (\% DM) & 35.2 & 36.2 & 30.5 & 20.0 \\
\hline Crude protein (\% DM) & 7.3 & 6.2 & 8.3 & 27.3 \\
\hline ADF (\% DM) & 33.6 & 20.4 & 38.0 & 20.3 \\
\hline NDF (\% DM) & 61.7 & 33.1 & 58.8 & 37.4 \\
\hline Soluble sugars and & & & & \\
\hline starch (\% DM) & 22.6 & 50.4 & 8.4 & 12.0 \\
\hline Ash (\% DM) & 6.6 & 3.9 & 7.7 & 11.2 \\
\hline Lipid (\% DM) & 2.0 & 3.2 & 1.9 & 4.3 \\
\hline OMD (\% DM) & ND & ND & 59.8 & 84.9 \\
\hline DCAD (mEq/kg DM) & ND & ND & 387 & 527 \\
\hline $\mathrm{ME}(\mathrm{MJ} / \mathrm{kg} \mathrm{DM})$ & 9.8 & 11.1 & 8.9 & 12.7 \\
\hline $\mathrm{pH}$ & 4.1 & 3.8 & ND & ND \\
\hline Lactic acid (\% DM) & 1.6 & 0.9 & ND & ND \\
\hline Ammonia (\% DM) & 1.5 & 5.6 & ND & ND \\
\hline
\end{tabular}

$\mathrm{ND}=$ not determined.

variable together with an indication of the nutritive value of the sample. Interpretation of this information requires some nutritional expertise, especially when forages are to be mixed, or supplemented, in order to meet production requirements. Professional nutrition backup is an important component of any feed analysis system, especially when forages yield unexpected analytical results.

Two sets of contrasting data given in Table 3, illustrate the extent to which feeds can differ in composition. One sample of maize silage has very little soluble carbohydrate (soluble sugars and starch) and a high concentration of structural fibre (NDF and ADF). This silage was made from stover (stalks and leaves of the plant with very little grain) and will be slow to degrade in the rumen. It will be of very low nutritive value to ruminants, in comparison with the maize silage sample 2, which has high concentrations of soluble carbohydrate, so that it would be an excellent supplement to pasture. The pasture samples also differ in nutritive value especially with regard to their concentration of crude protein and structural fibre, with consequent differences in estimated organic matter digestibility. These examples represent extremes for each feed type but the majority of samples fall midway between these values and require specialist skills for interpretation and use in animal feeding.

Several animal production models are available to assist farmers manage their livestock. Most have the capacity to input nutritional information to balance rations (where two or more dietary components are fed), identify nutrients appropriate to required levels of production or to predict production on the basis of feed supply and composition. Ration balancing models incorporate an animal feed requirement database against which feed composition data are matched in order to predict nutrient supply or productivity. These models 
provide an excellent avenue for using NIRS data especially when two or more feeds are offered.

\section{Uses and benefits of NIRS to research}

NIRS has widespread applications to agricultural research (e.g., Table 1) including to agronomic selection of forages for improved quality (Abrams et al. 1987; Baker \& Barnes 1990; Marten et al. 1989). The technique enables a portion of a plant to be taken for analysis, leaving sufficient material for propagation. NIRS can be used to screen for a wide range of characteristics (e.g., Table 3), and in forage research the most common uses are to analyse for the fibre (e.g., NDF) content of grasses and the protein content of grasses, legumes and herbs. The limitations to use of NIRS are defined by the capacity for accurate calibration and sample characteristics able to provide interpretable spectra. Exploratory projects at AgResearch (Palmerston North) include the use of NIRS to estimate condensed tannin concentrations in forages and to estimate diet composition from faeces analysis. Future research might include estimations of food intake (Murray et al. 1994; Unal \& Garnsworthy 1999). In all these applications NIRS can only be as good as the calibration data, derived from wet chemistry, but once calibration curves are in place NIRS does offer a rapid and cost effective analysis capable of screening large numbers of samples.

\section{Uses and benefits of NIRS to farming}

The benefits of good quality feed for ruminants are well known to farmers. It should, however, be reemphasised that the dairy cows in North America produce more than twice as much milk as cows of the same genetic merit in New Zealand (Ulyatt \& Waghorn 1993) and that the average growth rate of lambs in New Zealand is $100-140$ g/day compared with their potential of 300-400 g/day (Brown 1990).

The difference between actual and potential productivity is a consequence of nutrition - i.e., diet quality and voluntary intakes. Pasture is not an optimal diet for high producing ruminants (Ulyatt \& Waghorn 1993; Ulyatt et al. 1995), and NIRS estimation of pasture composition, with that of potential supplements provides an opportunity for designing a diet with a balance of nutrients best able to meet the needs of various classes of livestock. A balanced diet would be formulated on the basis of animal requirements for the intended level of production as well as on the basis of the compositions of the potential dietary constituents. This information can be provided by agricultural professionals, but complex decision making is assisted by the ration balancing model.
It is important to realise that pasture quality changes substantially over a growing season, so NIRS analyses will be a routine requirement if diets are to be of optimal nutritional quality. NIRS has the benefit of low cost compared to conventional wet chemistry so there is good potential for substantial economic benefits from ration balancing. The information presented in this paper related to the dairy industry because facilities are often in place for supplementary feeding and because of the efficiency with which supplemented balanced diets are used for milk production (NRC 1989).

When feedstuffs are bought and sold, an NIRS analyses will provide the buyer or seller with information about product quality. This should be a routine process in feed purchases because feeding strategies must be based on a cost/benefit analysis.

\section{Conclusion}

NIRS is a rapid, non-destructive and inexpensive technique for providing chemical and nutritional analyses of feed stuffs. The accuracy of predictions is dependent upon instrument calibration supported by good quality assurance protocols. The interpretation of data for animal feeding is best achieved using ration balancing software. NIRS can be used as an aid to plant selection for improved nutritive value and in the analysis of digestion in the ruminant. NIRS can benefit producers through formulation of rations best able to meet the nutritional requirements of various classes of livestock. Ration balancing software is able to match the nutritive value of each dietary component with the nutritive requirements, and the cost/benefits of supplementation.

\section{REFERENCES}

Abrams, S.M.; Shenk, J.S.; Westerhaus, M.O.; Barton, F.E. 1987. Determination of forage quality by near infrared reflectance spectroscopy: Efficiency of broad based calibration equations. Journal of dairy science 70: 806-803.

AFRC Technical Committee. 1993. Energy and protein requirements of ruminants. Wallingford, UK. CAB International.

ARC 1980. Nutrient requirements of ruminant livestock. Technical review by an Agricultural Research Council working party. Farnham Royal, Slough, Commonwealth Agricultural Bureau.

Baker, C.W.; Barnes, R. 1990. The application of near infra-red spectrometry to forage evaluation in the agricultural development and advisory service. In: Feedstuff evaluation. Eds. Wiseman, J.; Cole, D.J. London, Butterworths. 
Brown, C. 1990. An integrated herbage system for Southland and South Otago. Proceedings of the New Zealand Grassland Association 52: 119-122.

Clark, D.A.; Penno, J.W.; Niel, P.G. 1997. Nutritional merits and problems of pasture. pp. 397-418. In: Milk compositions, production and biotechnology. Eds. Welch, R.A.S.; Burns, D.J.W.; Davis, S.R.; Popay, A.I.; Prosser, C.G. Hamilton, New Zealand Pastoral Agricultural Research Institute Ltd.

Dowman, M.; Collins, F. 1982. The use of enzymes to predict the digestibility of animal feeds. Journal of the science of food and agriculture 33: 689-696.

Hulme, D.J.; Kellaway, R.C.; Boath, P.J.; Bennett, L. 1986: The CAM DAIRY model formulating and analysing Dairy Cow Rations. Agricultural systems 22: 81-108.

Marten, G.C.; Shenk, J.S.; Barton, F.E. 1989. Near infrared reflectance spectroscopy (NIRS): Analysis of forage quality. Agricultural Handbook No 643. Washington, D.C., US Government Printing Office.

Murray, I.; Morrin, M.; Paterson, R.M.; Rook, J. 1994. Rumen organic matter degradation kinetics from NIR reflectance spectra. pp. 474-478. In: Leaping ahead with near infrared spectroscopy, Eds. Batten, G.D.; Flinn, P.C.; Welsh, L.A.; Blakeney, A.B. Melbourne, NIR Spectroscopy Group, Royal Australian Chemical Institute.

NIRSystem. 1995. 'Feed \& Feed Ingredients Set, Calibration Set IC095IT'. NIRS 3 (Version 3.10) Routine Operation, Calibration Development \& Network Systems Management Manual, NIRSystems, USA.
NRC 1989. Nutrient requirements of dairy cattle, $6^{\text {th }}$ revised edition. Washington D.C., National Academy of Sciences.

Robards, G.E.; Radcliffe, J.C. 1990. Feeding standards for Australian Livestock: Ruminants. Melbourne, CSIRO.

Roughan G.P.; Hollan, R. 1977. Predicting in-vivo digestibilities of herbage by exhaustive enzymatic hydrolysis of cell walls. Journal of the science of food and agriculture 28: 1057-1064.

Shenk, J.S.; Westerhaus, M.O. 1991. Population structuring of near infrared spectra and modified partial least squares regression. Crop science 31: 1694-1696.

Shenk, J.S.; Westerhaus, M.O. 1993. Analysis of agriculture and food products by near infrared reflectance spectroscopy. Port Matilda, PA, Infrasoft International.

Ulyatt, M.J.; Lee, J.; Corson, D. 1995. Assessing feed quality. Ruakura Farmers Conference. 47; 59-62.

Ulyatt, M.J.; Waghorn, G.C. 1993. Proceedings of a workshop on 'Improving the quality and intake of pasture-based diets for lactating cows'. Department of Animal Science, Massey University. pp. 11-32.

Unal, Y.; Garnsworthy, P.C. 1999. Near-infrared reflectance spectroscopy for estimating food intake in house dairy cows. Proceedings of the British Society of Animal Science: 93.

Wilson, G.F. 1996. Mineral imbalance in the diet of dairy cows: Effects of fertiliser, and novel solutions to calcium and magnesium problems in dairy cows. Dairyfarming Annual Palmerston North 48: 140149. 